\title{
Direct responses in males and correlated responses for reproduction in females to selection for testicular size adjusted for body weight in young male lambs
}

\author{
C. S. Haley, G. J. Lee, M. Ritchie and R. B. Land $\dagger$ \\ A.F.R.C. Institute of Animal Physiology and Genetics Research, Edinburgh Research Station, \\ Roslin, Midlothian EH25 9PS, UK
}

\begin{abstract}
Summary. Selection based upon testicular diameter adjusted for body weight at 6,10 and 14 weeks of age was used to produce two lines of sheep, with either high or low testicular size. Ten generations of selection were carried out and the estimate of the realized heritability of the selection criterion was $0.53 \pm 0.01$. There were significant positive correlated responses to selection for testicular diameter at 6,10 and 14 weeks of age, but the correlated responses in body weight at these ages were negative. In mature females, there were significant negative correlated responses to selection in premating body weight in the 1st, 2nd and 3rd breeding season and in the day of the first oestrus in the 2 nd breeding season. Litter size per ewe mated had a small positive correlated response to selection in the second breeding season. This latter response appeared to be due to a positive correlated response in fertility, ewes from the High-line having a significantly higher probability of conceiving to a single mating than those from the Low-line. There was no significant correlated response in ovulation rate or litter size per ewe lambing and the genetic correlation between these traits and the selection criterion is likely to be close to zero. This may be due to the adjustment for body weight used, but it is possible that, in any event, body weight in young rams may be a better predictor of female ovulation rate than testicular diameter. These results do not rule out the possibility that testicular size in rams older than those selected would provide a good predictor of genetic merit for female ovulation rate.
\end{abstract}

Keywords: genetic selection; testicular diameter; ovulation rate; litter size; sheep

\section{Introduction}

Theoretical and experimental studies support the conclusion that increased ewe reproductive performance will improve economic efficiency by reducing the overhead costs of lamb production (Nitter, 1987). In Britain, the Meat and Livestock Commission (1987) include ewe reproductive performance in their selection indices for all except terminal sire breeds. However, the rate of genetic improvement of reproductive performance is restricted by the sex-limited nature of the traits, their expression in mature animals and their generally low heritabilities.

Rates of genetic improvement can be increased by selecting both males and females on the basis of an index of reproductive performance of their female relatives, in addition to their own records where these exist (Walkley \& Smith, 1980). None the less, if a trait could be identified which provides an indirect indicator of genetic merit for reproductive performance, and which could be measured in young males, selection utilizing information on this trait could increase rates of response substantially (Land, 1973). When the indirect indicator trait measured in males has a

$\dagger$ †eceased. 
moderate heritability and is highly genetically correlated with litter size, the predicted rate of genetic response, using this trait together with litter size, can approach double that predicted for selection based only on an index of litter size (Walkley \& Smith, 1980).

Testis size provides an easily measured integrated end point of gonadal response to trophic stimuli and is therefore a good potential candidate for a male indicator of genetic merit for female ovulation rate. This hypothesis has been validated in mice, with an estimated genetic correlation between testis weight and ovulation rate of 0.50 and a genetic regression of 2.9 ova per $100 \mathrm{mg}$ testis (Islam et al., 1976).

Given this theory, selection for testis size would be expected to change litter size in species such as cattle and sheep in which ovulation rate is considered to be the main factor limiting the number of offspring born (Bradford, 1972). This experiment was initiated to test this hypothesis in sheep. Preliminary results have been reported elsewhere (Land et al., 1980; Lee \& Land, 1985).

\section{Materials and Methods}

\section{Animals and selection}

Animals. The animals used were of the Finn-Dorset type, a synthetic breed with equal proportions of Finnish Landrace and Dorset Horn genes, created between 1965 and 1971 (Land \& McClelland, 1971). The initial selection was carried out on male lambs born in a housed flock in January 1972. All subsequent animals were managed on a traditional upland grassland sheep farming system, with mating over a 6-week period from early November and lambing the following April. The sheep were maintained on the Institute's Blythbank farm in Tweeddale, Southern Scotland. Testicular diameter and body weight were recorded at 6,10 and 14 weeks of age.

The experiment was initiated by selecting the 7 'highest' and 7 'lowest' rams on the basis of the selection criterion (see below) from a batch of 97 born in 1972 and mating these to 3-year-old ewes in the autumn of the same year. The 1973 born progeny of the 'high' and 'low' rams formed the High-line and the Low-line, respectively. From 1973 to 1982, about 7 males, with not more than 2 per half-sib group, were selected in each line on the basis of the selection criterion and mated to about 80 females in each year. Males were only used for a single season. Females were mostly 7 or 19 months of age at mating but, in some years, some older females had to be retained to maintain numbers. In each line, rams were randomly allocated to approximately equal numbers of ewes. Matings between animals with common grandparents were avoided. No selection was carried out on females, any surplus being culled so as to make half-sib families as equal in size as possible.

Selection criterion. Body weight $(\mathrm{kg})$ and total testicular diameter (the sum of the two individual diameters in $\mathrm{cm}$ ) were recorded in male lambs at 6,10 and 14 weeks of age. The diameter of each testis was recorded as the smallest separation of callipers which could be passed freely over the scrotal surface from the head to the tail of the epididymis, with the animal held in a semi-reclining position and the testis held tight against the scrotum.

In an attempt to take into account the high phenotypic correlation at all ages between testicular diameter and body weight, the regression of testicular diameter on body weight was calculated and used to adjust testicular diameter to the mean body weight at that age. In order to avoid prejudicing any genetic correlation between litter size and testicular diameter, no account was taken of birth-type when calculating the phenotypic regression of testicular diameter on body weight. The adjustment used was:

$$
\mathrm{T}_{a}{ }^{*}=\mathrm{T}_{a}-b_{\mathbf{P}}\left(\mathrm{T}_{a}, \mathrm{~W}_{a}\right)\left(\mathrm{W}_{a}-\overline{\mathrm{W}}_{a}\right)
$$

where $\mathrm{T}_{a}{ }^{*}$ is the adjusted testicular diameter at $a$ weeks, $\mathrm{T}_{a}$ is the observed testicular diameter at $a$ weeks, $\left(\mathrm{W}_{a}-\mathrm{W}_{a}\right)$ is the deviation of the individual body weight from the mean body weight at $a$ weeks and $b_{\mathrm{P}}\left(\mathrm{T}_{a}, \mathrm{~W}_{a}\right)$ is the phenotypic regression of testicular diameter on body weight at $a$ weeks. To give equal weighting to records obtained at 6,10 and 14 weeks, the deviations of an individual's adjusted diameter from the mean at each age were standardized to a variance of unity and the mean of the 3 standardized deviations formed the selection criterion. The means, variances and regressions used for these adjustments were those appropriate to the line, year of birth and age of measurement subclass.

Female traits. Reproduction traits were recorded in females in their 1 st and 2 nd breeding seasons, lambing at 1 and 2 years of age respectively. Vasectomized rams were run with all females after the lambs had been weaned (late July) in each year. The day of the first observed oestrus of the season (confirmed by a second observed oestrus 14-20 days later) was recorded as a day number from 1 January. All females were weighed on the day mating commenced, in early November of each year.

Ovulation rate, as the number of corpora lutea observed by laparoscopy, was recorded in all females born between 1973 and 1981 in their 1 st and 2 nd breeding season. In the first season, at 7 months of age, laparoscopy was performed 3-13 days after the oestrus when the animal was first mated. In the second breeding season, at 19 months of age, ovulation rate was recorded twice in consecutive cycles, the first record before, and the second record after the oestrus 
at which the animal was first mated. Ovulation rate was not recorded again in animals which subsequently returned to oestrus and were remated. The subsequent number of lambs born to each ewe was recorded for matings in all years up to 1985 .

Ewes in their 3rd breeding season were lambed in 1978, 1979, 1980, 1982 and 1985. Only premating body weights and litter sizes were recorded for ewes in their 3 rd breeding season.

Male fertility. A further study was performed to investigate the fertility of males from the selection lines. In 1982 , ten 7-month-old males from each line, for which monthly weights were being recorded, were mated to a total of 300 mature Welsh Mountian ewes. Each ram was marked and placed in a mating paddock with about 15 ewes which had previously been teased by vasectomized rams. Marked ewes were recorded as having been mated. After 25 days the ram was replaced by a Suffolk ram to investigate overall fertility of the ewes. The date of lambing and the lamb type were recorded to confirm the sire identity and date of mating.

\section{Analyses}

Inbreeding. The inbreeding coefficient of each animal was calculated using the numerator relationship method of Quaas (1976). Foundation animals were assumed to be unrelated.

Direct response to selection. The selection criterion was based on testicular diameter adjusted to the mean body weight at each age in each year and was expressed in terms of standard deviations from the line means recalculated each year. To simplify the analyses, observed testicular diameters for all lines, years and ages were adjusted to a body weight of $20 \mathrm{~kg}$ (the approximate mean body weight at 10 weeks of age; see Table 1), using the appropriate line, year of birth and age of measurement regression coefficient. The adjusted diameters at each age were standardized using the appropriate within-line standard deviation for that year and age. The mean of the 3 values was calculated to give a modified selection criterion. Within year and line subgroups, this modified criterion has a correlation of almost unity with the original criterion. As it is a mean value and not a deviation from a variable base, it can be accumulated over years, and so parameters of genetic response to selection can be calculated.

The realized heritability of the modified selection criterion was estimated using the recursive method of Thompson \& Juga (1989). This method predicts individual breeding values using parental information, but changes the regression coefficient each generation to allow for the effects of selection. An iterative process is performed to find the heritability which minimizes the squared differences of the observed values from those predicted. Thompson \& Juga (1989) have shown that the earlier methods of estimating realized heritability in populations with overlapping generations are essentially special cases of the recursive method. However, for comparison, the observed values were regressed on selection differentials calculated using the method of Pattie (1965) and that of Newman et al. (1973) (as discussed by James, 1986) to give two further estimates of realized heritability. None of these methods takes account of the effects of genetic drift. Although the estimates of realized heritability will not be biased, their standard errors will be underestimated. The extent of the underestimate will depend upon the heritability and population structure and is not simply calculated. However, the work of Atkins (1984), in a sheep population of a similar structure, suggests that any underestimation of the standard errors of the realized parameters will not be sufficient to prejudice the conclusions drawn from this experiment.

Correlated responses to selection. These analyses were carried out using the LSML76 computer package (Harvey, 1977). To obtain the genetic response to selection the estimated breeding value according to the method of Thompson \& Juga (1989) was fitted as an independent covariate. The regression on breeding value is an estimate of the genetic regression of each trait on the modified selection criterion. The model also included, as fixed effects, year of birth, litter size at birth ( 4 classes), rearing litter size (single, twin or bottle-fed) and age of dam at the birth of the lamb (1,2 or 3 or more years). The day of birth of the animal (as a day number from 1 January), the inbreeding coefficient of the individual and that of its dam were all fitted in the analyses as continuous independent covariates. Phenotypic variances and covariances were estimated as residual variances and covariances within year and line in a model omitting breeding value.

Analysis of fertility. Two estimates of fertility were analysed using the GLIM package (Baker \& Nelder, 1978): these were overall conception in the season, irrespective of the number of oestrous periods at which mating took place, and conception at the first oestrus when the animal was mated (first service). Both traits were analysed in the 1 st and 2nd breeding seasons. The traits were treated as binomial probabilities using a logit transformation to convert the data to an underlying linear scale. The effects fitted in the model were those in the genetic response analysis described above. In addition, ewe premating weight was included in some models. Reconversion from the underlying scale to the probability of conception at specified levels of the breeding values, at base levels of the other classified factors, and base values for the independent variables, uses:

$$
P=\frac{\exp (L)}{1+\exp (L)}
$$

where $P$ is the probability of conception and $L$ is the estimate on the underlying scale. Using this formula, probabilities of conception overall and to first service were predicted over a range of breeding values, for each breeding season.

Analyses of the fertility of Welsh ewes mated to Finn-Dorset rams were also performed in the same manner. Overall conception to any mating (by Finn-Dorset or Suffolk ram) and conception to one Finn-Dorset mating were 
treated as binomial probabilities and regressed on the estimated breeding value of the Finn-Dorset ram. In some analyses the mean of the 2-monthly weight measurements of the ram nearest to the breeding season was included as a covariate.

\section{Results}

\section{Animals}

An average of 45.7 male lambs in the High-line and 33.3 male lambs in the Low-line were tested per year; 7.81 male lambs sired progeny in the High-line and 7.55 in the Low-line each year. In the High-line 33.6 females, and in the Low-line 28.7 females, were retained per year and mated in their 1 st and 2 nd breeding seasons.

Inbreeding started accumulating after 3 years of selection. Thereafter it accumulated at about $1 \%$ per year and was $7.4 \%$ on average in the High-line and $7.8 \%$ on average in the Low-line in lambs born in the final year (1983).

\section{Male traits}

Using the method of Thompson \& Juga (1989), the realized heritability of the modified selection criterion was estimated at $0 \cdot 530 \pm 0 \cdot 013$. The means of the modified selection criterion for male lambs born in each line in each year are shown in Fig. 1, together with the annual difference between the line means. The difference in predicted breeding values for the modified selection criterion between animals born into the High and Low lines in the final year (i.e. 1983) was $3.59 \pm 0.04$ (approximately $+2 \cdot 1$ and -1.5 relative to the foundation population in the High and Low lines, respectively). The realized heritability estimated by the method of Newman et al. (1973) was $0.506 \pm 0.012$ and by the Pattie (1965) method was $0.487 \pm 0.011$.

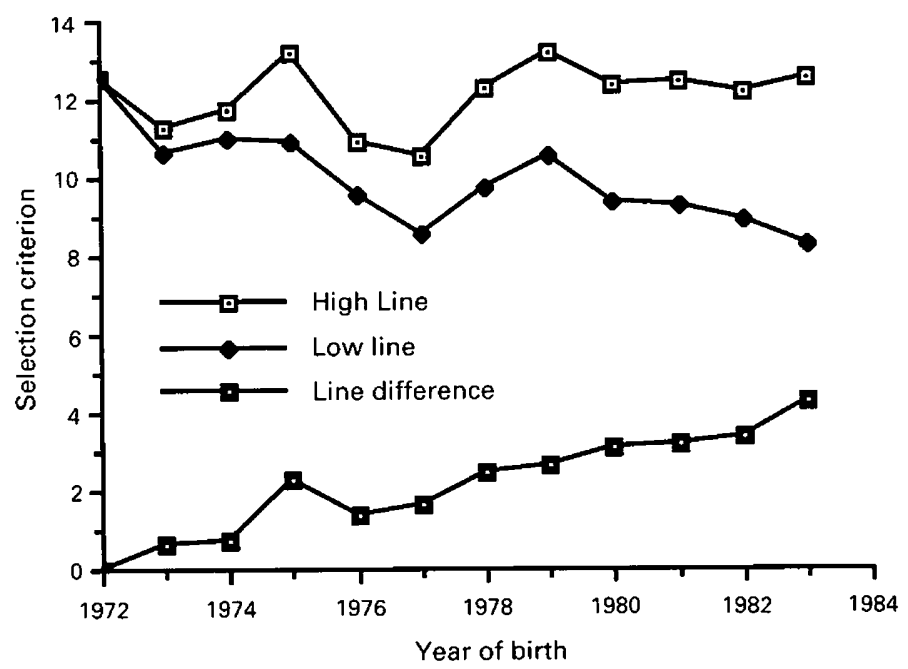

Fig. 1. Mean values of the selection criterion of rams in the High and Low selection lines each year and the annual difference between line means.

The estimated least squares means of male traits are shown in Table 1 together with the estimates of their genetic regressions on the predicted breeding values of the modified selection criterion. The genetic regression for the modified selection criterion was very close to its expectation of unity. Birth weight showed no correlated response to selection, but the genetic regressions for weight at 6 , 
10 and 14 weeks were negative and those at 10 and 14 weeks were significant. Estimates of the genetic regressions of testicular diameter at 6,10 and 14 weeks on the modified selection criterion were all positive and highly significant. The mean total testicular diameter at 10 weeks of age (unadjusted for body weight) is shown plotted for each line on an annual basis in Fig. 2.

Table 1. Means, genetic regressions on the selection criterion and predicted divergence between traits in the High and Low lines of males born in the final year (1983)

(see text for further details)

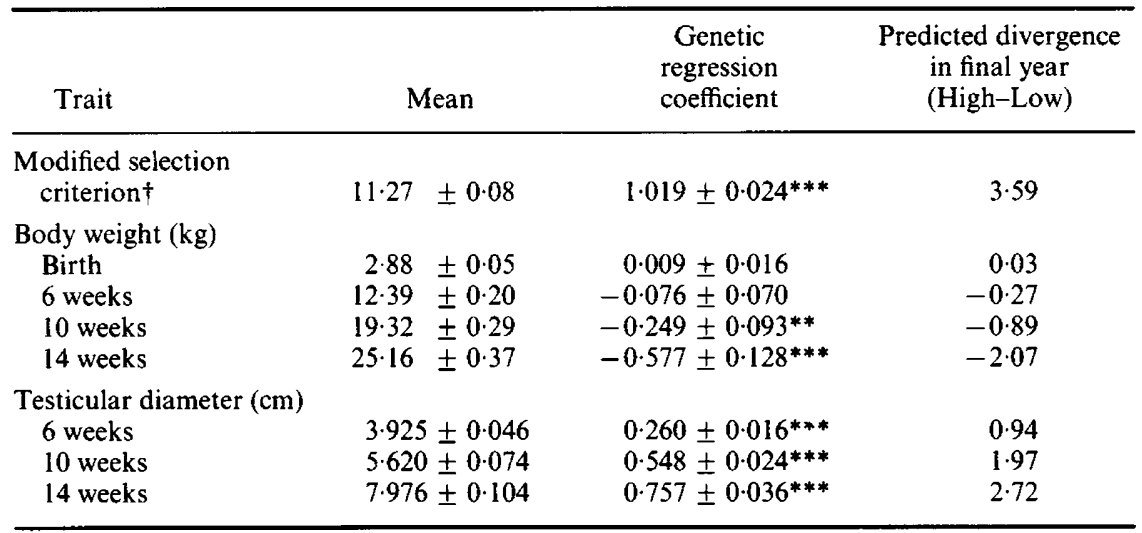

$\nmid$ Testicular diameter adjusted for body weight.

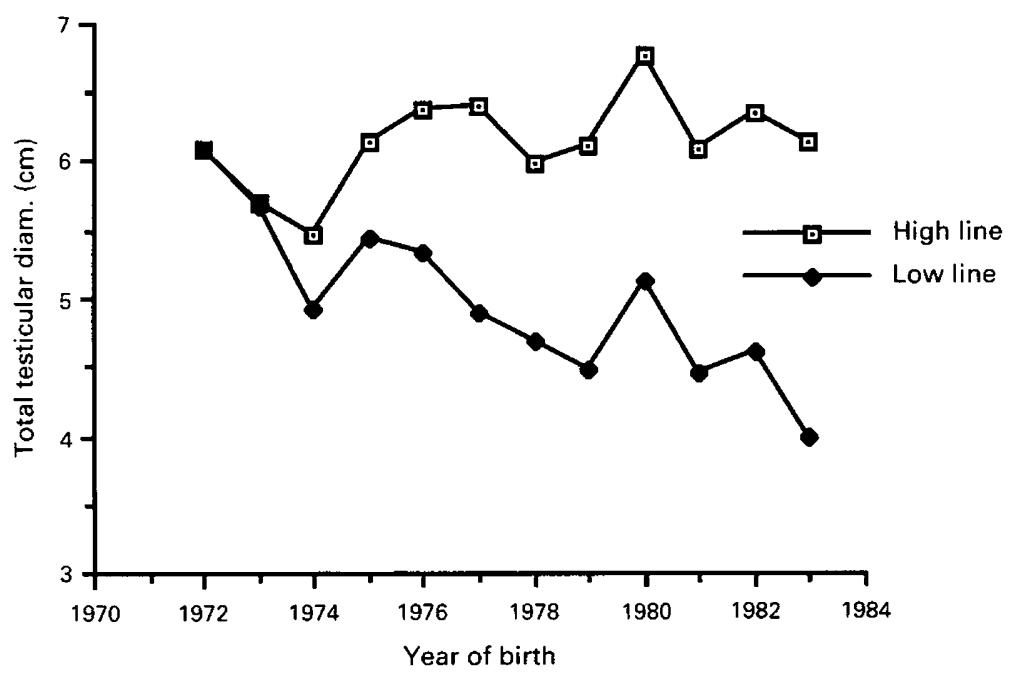

Fig. 2. Mean total testicular diameter of 10 -week-old male lambs in the High and Low selection lines each year.

The predicted difference between the lines for animals born in the final year for correlated traits, based on the genetic regressions and the final year line difference in predicted breeding value for the modified selection criterion, are shown in Table 1. The proportionate differences increased with age, resulting in between line differences at 6 and 14 weeks of age, respectively, of 0.022 and 0.082 of the mean for body weight and 0.239 and 0.341 of the mean for testicular diameter.

Estimates of phenotypic variances of traits recorded in males and the phenotypic correlation between these traits are shown in Table 2 . The estimated correlations between birth weight and 
body weights at 6,10 and 14 weeks were all large, but declined with age. The correlations of birth weight with testicular diameter were moderate in size and only decreased slightly with age. Estimates of phenotypic correlations within and between weight and testicular measures were all very high. Phenotypic correlations of the modified selection criterion with testicular diameters were high but, as planned, were virtually zero wih body weights.

Table 2. Phenotypic within-line variances (emboldened on diagonal) and phenotypic within-line correlations (above diagonal) of male traits, together with the number of records involved in each variance

\begin{tabular}{|c|c|c|c|c|c|c|c|c|}
\hline & \multicolumn{4}{|c|}{ Body weight $(\mathrm{kg})$} & \multicolumn{3}{|c|}{ Testicular diameter $(\mathrm{cm})$} & \multirow{2}{*}{$\begin{array}{l}\text { Modified } \\
\text { selection } \\
\text { criterion }\end{array}$} \\
\hline & Birth & 6 weeks & 10 weeks & 14 weeks & 6 weeks & 10 weeks & 14 weeks & \\
\hline No. of records & 869 & 803 & 869 & 803 & 803 & 869 & 803 & 869 \\
\hline $\begin{array}{l}\text { Body weight }(\mathrm{kg}) \\
\text { Birth } \\
6 \text { weeks } \\
10 \text { weeks } \\
14 \text { weeks }\end{array}$ & $0 \cdot 337$ & $\begin{array}{l}0.61^{* * *} \\
\mathbf{5 \cdot 2 9}\end{array}$ & $\begin{array}{l}0.52^{* * *} \\
0 \cdot 86^{* * *} \\
10 \cdot 92\end{array}$ & $\begin{array}{l}0 \cdot 44^{* * *} \\
0 \cdot 77^{* * *} \\
0 \cdot 86^{* * *} \\
\mathbf{1 7 \cdot 2 1}\end{array}$ & $\begin{array}{l}0.36^{* * *} \\
0.73^{* * *} \\
0.64^{* * *} \\
0.56^{* * *}\end{array}$ & $\begin{array}{l}0.33^{* * *} \\
0.68^{* * *} \\
0 \cdot 72^{* * *} \\
0.62^{* * *}\end{array}$ & $\begin{array}{l}0.31^{* * *} \\
0.62^{* * *} \\
0.65^{* * *} \\
0.68^{* * *}\end{array}$ & $\begin{array}{r}-0.08 \\
0.07 \\
0.02 \\
-0.02\end{array}$ \\
\hline $\begin{array}{l}\text { Testicular diamete } \\
6 \text { weeks } \\
10 \text { weeks } \\
14 \text { weeks }\end{array}$ & (cm) & & & & $0 \cdot 273$ & $\begin{array}{l}0 \cdot 78^{* * *} \\
0 \cdot 726\end{array}$ & $\begin{array}{l}0.66^{* * *} \\
0.82^{* * *} \\
1.460\end{array}$ & $\begin{array}{l}0.58^{* * *} \\
0.62^{* * *} \\
0.59^{* * *}\end{array}$ \\
\hline Modified selection & riterion & & & & & & & $0 \cdot 732$ \\
\hline
\end{tabular}

\section{Female traits}

Estimated least squares of means of female traits are shown in Table 3 together with the estimate of their genetic regression on the modified selection criterion and the predicted divergence between lines for animals born in 1983 .

Table 3. Means, genetic regressions on the selection criterion and predicted divergence for female traits between the High and Low lines of animals born in the final year (1983) (see text for further details)

\begin{tabular}{|c|c|c|c|}
\hline Trait & Mean & $\begin{array}{l}\text { Genetic } \\
\text { regression } \\
\text { coefficient }\end{array}$ & $\begin{array}{l}\text { Predicted } \\
\text { divergence } \\
\text { in final year } \\
\text { (High-Low) }\end{array}$ \\
\hline Birth weight $(\mathrm{kg})$ & $2 \cdot 71 \pm 0.05$ & $0.015 \pm 0.017$ & 0.05 \\
\hline Day of first oestrus in Ist breeding season & $338 \cdot 19 \pm 2 \cdot 72$ & $-1.557 \pm 0.926$ & $-5 \cdot 59$ \\
\hline Pre-mating weight in 1 st breeding season $(\mathrm{kg})$ & $30.41 \pm 0.42$ & $-0.777 \pm 0.142 * * *$ & $-2 \cdot 79$ \\
\hline Ovulation rate in 1 st breeding season & $1.82 \pm 0.07$ & $0.036 \pm 0.026$ & $0 \cdot 13$ \\
\hline Litter size/ewe mated in 1 st breeding season & $0.93 \pm 0.08$ & $0.034 \pm 0.026$ & $0 \cdot 12$ \\
\hline Litter size/ewe lambing in 1st breeding season & $1.41 \pm 0.06$ & $-0.009 \pm 0.024$ & -0.03 \\
\hline Day of first oestrus in 2 nd breeding season & $253.85 \pm 2.33$ & $-2.833 \pm 0.793 * * *$ & $-10 \cdot 17$ \\
\hline Pre-mating weight in 2 nd breeding season $(\mathrm{kg})$ & $47.44 \pm 0.58$ & $-1.990 \pm 0.197 * * *$ & $-7 \cdot 14$ \\
\hline 1st ovulation rate record in 2 nd breeding season & $2.01 \pm 0.07$ & $0.029 \pm 0.025$ & $0 \cdot 10$ \\
\hline 2nd ovulation rate record in 2 nd breeding season & $2.03 \pm 0.07$ & $0.009 \pm 0.026$ & $0 \cdot 03$ \\
\hline Litter size/ewe mated in 2 nd breeding season & $1.64 \pm 0.07$ & $0.063 \pm 0.025^{*}$ & $0 \cdot 23$ \\
\hline Litter size/ewe lambing in 2 nd breeding season & $1.84 \pm 0.07$ & $0.011 \pm 0.027$ & 0.04 \\
\hline Pre-mating weight in 3rd breeding season $(\mathrm{kg})$ & $58.94 \pm 1.13$ & $-3 \cdot 340 \pm 0.420^{* * *}$ & -11.99 \\
\hline Litter size/ewe mated in 3rd breeding season & $1.93 \pm 0.15$ & $0.068 \pm 0.055$ & 0.24 \\
\hline Litter size/ewe lambing in 3rd breeding season & $2.08 \pm 0.15$ & $-0.000 \pm 0.065^{* * *}$ & -0.00 \\
\hline
\end{tabular}


The genetic regression of birth weight on the modified selection criterion was very small and not significant. The genetic regressions for premating weights in all seasons were negative and highly significant. There was no evidence that these regressions were non-linear. The predicted line difference in premating body weight was 0.092 proportionate to the mean in the first breeding season and $0 \cdot 151$ and 0.203 in the 2 nd and 3 rd breeding seasons, respectively. Regressions for day of first oestrus were negative for both seasons (High-line animals show oestrus earlier) and highly significant in the 2 nd breeding season. All the genetic regressions of ovulation rate on the modified selection criterion were positive but small, and none approached significance. Genetic regressions for litter size per ewe lambing were very close to zero and not significant. Genetic regressions for litter size per ewe mated were positive and that in the 2 nd breeding season was significantly different from zero.

Estimates of the phenotypic variance of female traits and the phenotypic correlations between them are shown in Table 4. Birth weight had quite high correlations with premating weight in all breeding seasons and significant positive correlations with all measures of ovulation rate, but not with measures of litter size. Premating weights were highly correlated with one another, and in the Ist and 2 nd seasons each had significant positive correlations with all measures of ovulation rate and litter size recorded in the same season. Day of first oestrus in the first season was significantly negatively correlated with premating weight, ovulation rate and both measures of litter size in the 1 st season and with the first ovulation rate record and litter size per ewe mated in the 2 nd breeding season. However, day of first oestrus in the 2 nd season had no significant correlations with other traits. Ovulation rates were significantly positively correlated with each other and with measures of litter size both within and between seasons. Litter size per ewe mated was not significantly correlated between seasons, but litter size per ewe lambing did have significant positive correlations between seasons, although not between the 1 st and $3 \mathrm{rd}$ season.

Results of the analyses of fertility are shown in Table 5. These demonstrated a significant positive regression of fertility on the modified selection criterion. The effect was more marked for analyses of conception to first service than overall conception, as ewes not holding to their first service would be remated at one or more oestrous periods. There was also a tendency for the regressions to increase with the age of ewe. When ewe premating body weight was included in the model, regressions of fertility on body weight were positive and significant in the 1st breeding season and for overall fertility in the 2 nd season and small and not significant otherwise. When the regressions on body weight were significant, the regressions of fertility on the modified selection criterion were increased.

Results obtained from mating Welsh ewes to Finn-Dorset rams from the selection lines are shown in Table 6 . As expected, the overall conception, after remating non-pregnant ewes to Suffolk rams, was not associated with the breeding value of the Finn-Dorset ram to which ewes were first mated. Conception to one mating by a Finn-Dorset ram was negatively associated with the breeding value of the ram, but the regression was not significant, so there appears to be no difference in fertility between rams from the High and Low lines. However, the underlying variate had a significant positive regression on ram body weight $(0.141 \pm 0.034)$ when this was added to the model. After fitting body weight there was a positive, but still non significant, regression of the underlying variate on breeding value of the ram. Therefore, when ram body weight is not fitted, the negative regression on breeding value could be associated with the smaller size of the High-line animals.

\section{Discussion}

The estimate of 0.53 presented here confirmed the previously reported (Lee \& Land, 1985) high heritability of the modified selection criterion, testicular size adjusted for its phenotypic association with body weight in young rams. The work also confirmed the possibility of making genetic 


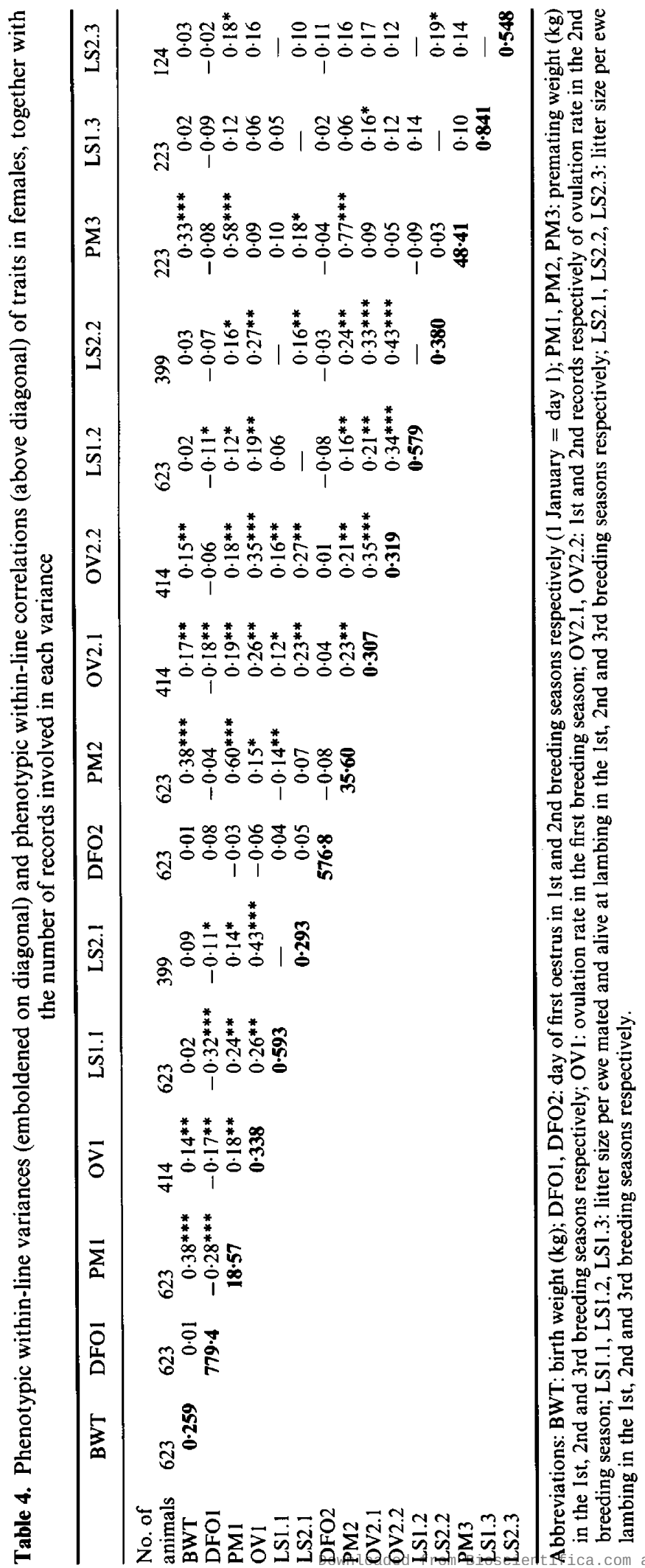


Table 5. The predicted overall probability of a ewe lambing, and the predicted probability of a ewe lambing to first service for breeding values of the selection criterion equivalent to that in the foundation population (0.0), and for animals born in 1983 in the High line $(+2 \cdot 1)$ and in the Low line $(-1 \cdot 5)$, with the regressions of the underlying variate on ewe premating body weight and on predicted breeding value

\begin{tabular}{|c|c|c|c|c|c|c|}
\hline \multirow{2}{*}{$\begin{array}{l}\text { Predicted } \\
\text { breeding } \\
\text { value }\end{array}$} & \multicolumn{2}{|c|}{ Season 1} & \multicolumn{2}{|c|}{ Season 2} & \multicolumn{2}{|c|}{ Season 3} \\
\hline & Overall & $\begin{array}{l}\text { First } \\
\text { service }\end{array}$ & Overall & $\begin{array}{l}\text { First } \\
\text { service }\end{array}$ & Overall & $\begin{array}{l}\text { First } \\
\text { service }\end{array}$ \\
\hline$+2 \cdot 1$ & $0 \cdot 800$ & 0.694 & 0.966 & 0.879 & 0.997 & 0.973 \\
\hline $0 \cdot 0$ & 0.745 & 0.608 & 0.921 & 0.727 & 0.993 & 0.895 \\
\hline$-1 \cdot 5$ & 0.700 & 0.542 & 0.861 & 0.564 & 0.988 & 0.749 \\
\hline $\begin{array}{l}\text { Regression on breeding value } \\
\text { (model omitting ewe body weight) }\end{array}$ & $\begin{array}{l}0 \cdot 15 \pm \\
0 \cdot 07\end{array}$ & $\begin{array}{l}0.18 \pm \\
0 \cdot 07^{*}\end{array}$ & $\begin{array}{l}0 \cdot 42 \pm \\
0 \cdot 13^{* * *}\end{array}$ & $\begin{array}{l}0 \cdot 48 \pm \\
0 \cdot 09^{* * *}\end{array}$ & $\begin{array}{l}0.36 \pm \\
0 \cdot 32\end{array}$ & $\begin{array}{l}0 \cdot 70 \pm \\
0 \cdot 19^{* * *}\end{array}$ \\
\hline $\begin{array}{l}\text { Regression on breeding value } \\
\text { (model including ewe body weight) }\end{array}$ & $\begin{array}{l}0 \cdot 24 \pm \\
0 \cdot 08^{* *}\end{array}$ & $\begin{array}{l}0.26 \pm \\
0.07^{* * *}\end{array}$ & $\begin{array}{l}0 \cdot 51 \pm \\
0 \cdot 13^{* * *}\end{array}$ & $\begin{array}{l}0.49 \pm \\
0 \cdot 09^{* * *}\end{array}$ & $\begin{array}{l}0.33 \pm \\
0.37\end{array}$ & $\begin{array}{l}0.60 \pm \\
0.21^{* *}\end{array}$ \\
\hline Regression on ewe body weight & $\begin{array}{l}0 \cdot 10 \pm \\
0 \cdot 02^{* * *}\end{array}$ & $\begin{array}{l}0 \cdot 09 \pm \\
0 \cdot 02^{* * *}\end{array}$ & $\begin{array}{l}0.05 \pm \\
0 \cdot 02^{*}\end{array}$ & $\begin{array}{l}0.01 \pm \\
0.01\end{array}$ & $-0.01 \pm$ & $\begin{array}{r}-0.03 \\
0.03\end{array}$ \\
\hline
\end{tabular}

Table 6. The predicted probability of a Welsh ewe lambing to a single service by a Finn-Dorset ram, and the overall probability of lambing following subsequent exposure to a Suffolk ram, are given for breeding values of the selection criterion equivalent to that in the foundation population (0.0), and for animals born in 1983 in the High line $(+2 \cdot 1)$ and in the Low line $(-1 \cdot 5)$, with the regressions of the underlying variate on ram predicted breeding value

\begin{tabular}{|c|c|c|c|c|}
\hline & \multicolumn{3}{|c|}{$\begin{array}{l}\text { Predicted breeding value } \\
\text { of the Finn-Dorset ram }\end{array}$} & \multirow{2}{*}{$\begin{array}{l}\text { Regression of } \\
\text { underlying variat } \\
\text { on breeding value }\end{array}$} \\
\hline & $-1 \cdot 5$ & 0 & $+2 \cdot 1$ & \\
\hline Conception overall & 0.911 & 0.915 & 0.920 & $0.034 \pm 0.115$ \\
\hline $\begin{array}{l}\text { Conception to one Finn-Dorset mating } \\
\text { (omitting ram body weight from model) }\end{array}$ & 0.681 & 0.647 & 0.597 & $-0 \cdot 102 \pm 0 \cdot 065$ \\
\hline $\begin{array}{l}\text { Conception to one Finn-Dorset mating } \\
\text { (including ram body weight in model) }\end{array}$ & 0.611 & 0.647 & 0.694 & $0.102 \pm 0.084$ \\
\hline
\end{tabular}

alterations in components of female reproduction by selection on male traits. Although ovulation rate and litter size per ewe lambing were not changed by selection, correlated responses in day of first oestrus in the 2 nd breeding season and litter size per ewe mated were observed.

The lack of a correlated response in ovulation rate and a negative correlated response in body weight to selection could be due to the exact nature of the criterion used. Purvis et al. (1988) have argued that both the lack of response in ovulation rate and the negative correlated response in body weight observed in these lines are due to the phenotypic adjustment for body weight employed in this experiment. It is difficult to explore the consequences of weight adjustment on the index actually used due to its complexity. However, some conclusions can be drawn under the simplifying assumption that the results would have been little different had selection been based on testicular size adjusted for its phenotypic regression on body weight at a single age (for example, 10 weeks). This assumption is probably justified, as the genetic correlations between testicular size at 6,10 and 14 weeks of age, or between body weight at 6,10 and 10 weeks of age, are likely to be close to unity.

The consequences of a model with selection on testicular size adjusted for its phenotypic regression on body weight at a single age are explored in the 'Appendix'. The main conclusions are, firstly, that selection will lead to a negative correlated response in body weight when the phenotypic 
regression of testicular size on body weight is greater than the genetic regression. This may often be the case as there is no theoretical reason for these two regressions to be the same. Secondly, if it assumed that selection for testicular size adjusted for body weight at a single age would produce no correlated change in ovulation rate, then the absolute merit of using either testicular size unadjusted for body weight, or body weight itself, as indirect indicators of ovulation rate cannot be estimated. However, selection for testicular size on its own is likely to be less effective (estimated at $72 \%$ as effective) at changing ovulation rate than is selection for body weight.

Other workers have found some evidence of significant positive genetic associations between testicular size and aspects of female reproductive performance in sheep: e.g. Hanrahan \& Quirke (1982) in ovulation rate-selected lines, Knight (1984) in fertility-selected lines, Burfening \& Tulley (1986) in prolificacy-selected lines, Ricordeau et al. (1986) with induced prolificacy and Purvis et al. (1988) with ovulation rate. However, not all associations in these studies were significant and in other studies (Ricordeau et al., 1979, 1984), no evidence of positive associations was found. Given the low heritability and repeatability of female reproductive traits, it is not surprising that estimates of correlations have large standard errors and some are not significantly greater than zero. The overall pattern is for positive associations between testicular size and female reproductive performance. This pattern is repeated in mice (Islam et al., 1976; Hill et al., 1990), cattle (Toelle \& Robison, 1985a) and pigs (Schinckel et al., 1983; Toelle \& Robison, 1985b). As yet no study has fully analysed genetic relationships between testicular size and female reproductive traits when body size or weight is taken into account. As Purvis et al. (1988) suggest and as shown here, this must be done before the merit of testis size per se as an indirect indicator of female reproductive performance can be fully evaluated.

In addition to body weight, a further variable which requires to be taken into account is the effect of the age of the male at measurement on the genetic correlation between testicular size and female reproductive performance. There is little evidence on this point at present. The study of Purvis et al. (1988) looked at testicular size over a range of ages and found evidence of a positive correlation with ovulation rate, but no evidence of variation with age, although their first records were not taken until males were 5 months old. McNeilly et al. (1986) studied males from the experiment reported here and found that testicular growth was much more rapid up to 16 weeks of age in High-line males than in Low-line males. Testicular growth virtually ceased at 16 weeks of age in High-line males, but continued in Low-line males until 20 weeks of age, by which time rams of the two lines had virtually the same testicular diameters. Thereafter, rams in the two lines maintained approximately similar testicular diameters. Selection has resulted in a more rapidly growing testis in High-line rams, but not in greater size of the mature testis. It is possible that mature testis size provides a better predictor of female ovulation rate than testis growth in young males. If this is the case, selection in rams of 20-30 weeks of age, when the testes have stopped growing before the first breeding season, would have been more effective than the criterion actually used.

Selection has produced a positive correlated response in litter size per ewe mated which appeared to be due to a change in fertility. The results from within-line matings (Table 5) suggest a large alteration in fertility by the end of selection. The effect was particularly marked for results from first service only. This is to be expected, as differences in fertility will to some extent be masked in the overall conception rate by the remating of animals which do not conceive to a previous mating. The effect is also greater in the second breeding season of the ewes than in the first, suggesting that it is a trait of mature ewes, and not just associated with young ewes, for example via earlier maturation of the reproductive system in High-line ewes.

Mating of Finn-Dorset rams to mature Welsh ewes demonstrated that the fertility effect is not a trait of the males, as might have been expected, for males with higher breeding values tend to have lower fertilities. The significant positive regression of fertility on the weight of the ram indicates that any correlated change in male fertility with selection is probably due to the change in body weight. 
The positive regression of fertility on ram body weight suggests that the correlated change in overall line fertility could be associated with an interacton between male and female body weights. For example, young rams may be more prone to bullying by heavier ewes, and have more success in mating the lighter ewes in the High selection line, leading to higher apparent fertility in this line. This hypothesis is supported by the observation that the association of fertility with breeding value is then more marked in older ewes, for which the proportionate difference in ewe body weights is greater. However, the analyses of within-line fertility including ewe premating body weight as an additional covariate show that there are positive associations between fertility and ewe body weight in the first breeding season, which decline to zero in later seasons. The inclusion of ewe premating body weight does not greatly change the regressions of fertility on breeding value. The association between predicted breeding value for the modified selection criterion and fertility is therefore not due to an effect of ewe body weight on the ability of young rams to mate mature ewes successfully. Furthermore, litter size per ewe lambing did not show a correlated response to selection (Table 3 ). There is therefore no evidence for a correlated response in prenatal survival, which could have explained a change in fertility due to a higher incidence of total loss of fertilized ova in Low-line animals than in High-line animals. The evidence therefore appears to point to some effect of the breeding value for the modified selection criterion on fertility per se.

The relatively large correlated response in ewe fertility may indicate the value of selection for testicular size for the improvement of conception rate. There have been some other tentative pointers in this direction in work on cattle (Toelle \& Robison, 1985a) and on mice (Hill et al., 1990). However, we cannot at present suggest a mechanism to explain the correlation and these results should be treated with caution until confirmed by research in other populations.

Finally, the results of this study re-emphasize the conclusion reached previously (Land et al., 1982; Hill, 1985; Haley et al., 1987), that, in the search for indirect indicator traits, the best strategy is to select for the trait of primary interest (for example, ovulation rate, growth rate, lean content) in experimental flocks. The selected lines can then be examined for correlated responses for a number of potential indicator traits over a period of time to discover the most promising trait and to show the most effective age of measurement and means of adjustment for other variables, such as body size. This approach would overcome the problem faced in this experiment, of not knowing what effect relatively minor changes in the modified selection criterion (such as altering the weight adjustment or changing the age of selection) might have had. Although the modified selection criterion used produced no correlated change in ovulation rate, the results of this experiment provide no evidence on the hypothesis that selection of older ram lambs, at a time when the testes had stopped growing, would provide a good predictor of female merit for ovulation rate.

We thank the staff of Blythbank Farm, particularly J. C. Harris, J. Bracken, P. Davis and D. J. Drury, for their care of the animals; H. Kelly for meticulous record keeping; B. Wilson for assistance with ovulation rate recording; and $\mathrm{R}$. Thompson and $\mathrm{D}$. Sales for useful discussions.

\section{Appendix}

The theoretical consequences of adjusting testicular size for its phenotypic regression on body weight can be explored in a way similar to the exploration performed by Purvis et al. (1988). Based on measurements taken at 10 weeks of age the selection criterion used would be:

$$
\mathrm{T}^{*}=\mathrm{T}-b_{\mathrm{p}}(\mathrm{T}, \mathrm{W} 10)(\mathrm{W} 10-\mathrm{W} \overline{1} 0)
$$

where $T^{*}$ is testicular diameter adjusted for body weight, $T$ is testicular diameter at 10 weeks of age (W10 - W $\overline{1} 0)$ is the deviation from the mean body weight at 10 weeks of age and $b_{p}(\mathrm{~T}, \mathrm{~W} 10)$ is the coefficient of the phenotypic regression of testicular diameter on body weight at 10 weeks of age. 
The genetic covariance of W10 with $\mathrm{T}^{*}$ (i.e. $\operatorname{Cov}_{A}\left(\mathrm{~T}^{*}, \mathrm{~W} 10\right)$ ) will dictate the correlated change in W10 with selection on $T^{*}$, this is:

$$
\operatorname{Cov}_{A}\left(\mathrm{~T}^{*}, \mathrm{~W} 10\right)=\operatorname{Cov}_{A}(\mathrm{~T}, \mathrm{~W} 10)-b_{p}(\mathrm{~T}, \mathrm{~W} 10) \mathrm{V}_{A}(\mathrm{~W} 10)
$$

where $\operatorname{Cov}_{A}(\mathrm{~T}, \mathrm{~W} 10)$ is the genetic covariance between testicular diameter and body weight at 10 weeks of age and $V_{A}\left(W_{10}\right)$ is the genetic variance of body weight at 10 weeks of age. Body weight at 10 weeks of age will decline with selection on $T^{*}$ if $\operatorname{Cov}_{A}\left(T^{*}, W 10\right)$ is negative, this occurs if:

$$
b_{p}(\mathrm{~T}, \mathrm{~W} 10)>\frac{\operatorname{Cov}_{A}(\mathrm{~T}, \mathrm{~W} 10)}{\mathrm{V}_{A}(\mathrm{~W} 10)}
$$

that is, if the phenotypic regression of testicular diameter on body weight is greater than the genetic regression.

The correlated response in body weight of mature females $(\mathrm{Wm})$ will depend upon the genetic covariance between $\mathrm{T}^{*}$ and $\mathrm{Wm}$ which will be negative if:

$$
b_{p}(\mathrm{~T}, \mathrm{~W} 10)>\frac{\operatorname{Cov}_{A}(\mathrm{~T}, \mathrm{Wm})}{\operatorname{Cov}_{A}(\mathrm{~W} 10, \mathrm{Wm})} .
$$

If the genetic correlation between testicular diameter at 10 weeks of age and body weight in mature females $\left(r_{A}(\mathrm{~T}, \mathrm{Wm})\right)$ is solely a consequence of the genetic correlation between testicular diameter and body weight at 10 weeks of age $\left(r_{A}(\mathrm{~T}, \mathrm{~W} 10)\right)$ and that between body weight in 10 week old males and mature females $\left(r_{A}(\mathrm{~W} 10, \mathrm{Wm})\right)$, then:

$$
r_{A}(\mathrm{~T}, \mathrm{Wm})=r_{A}(\mathrm{~T}, \mathrm{~W} 10) r_{A}(\mathrm{~W} 10, \mathrm{Wm}) .
$$

Then it follows that for the correlated response of mature ewe body weight to be negative:

$$
b_{p}(\mathrm{~T}, \mathrm{~W} 10)>\frac{\operatorname{Cov}_{A}(\mathrm{~T}, \mathrm{~W} 10)}{\mathrm{V}_{A}(\mathrm{~W} 10)},
$$

as before. Therefore the conclusion is reached that the direction of correlated responses in body weight to selection on testicular diameter adjusted for its phenotypic regression on body weight may largely be determined by the relative magnitudes of the phenotypic and genetic regressions. If, as may often be the case, the phenotypic regression is greater than the genetic regression, the correlated response will be negative.

The genetic covariance between ovulation rate $(\mathrm{OR})$ and $\mathrm{T}^{*}\left(\mathrm{i} . \mathrm{e} \cdot \mathrm{Cov}_{A}\left(\mathrm{~T}^{*}, \mathrm{OR}\right)\right.$ ) will dictate the magnitude of the correlated response in $\mathrm{OR}$ when selection is on $\mathrm{T}^{*}$, this is:

$$
\operatorname{Cov}_{A}\left(\mathrm{~T}^{*}, \mathrm{OR}\right)=\operatorname{Cov}_{A}(\mathrm{~T}, \mathrm{OR})-b_{p}(\mathrm{~T}, \mathrm{~W} 10) \operatorname{Cov}_{A}(\mathrm{~W} 10, \mathrm{OR})
$$

where $\operatorname{Cov}_{A}(T, O R)$ is the genetic covariance between testicular diameter and ovulation rate and $\mathrm{Cov}_{A}(\mathrm{~W} 10, \mathrm{OR})$ is the genetic covariance between weight at 10 weeks and ovulation rate. Where there is no correlated response in ovulation rate with selection on $\mathrm{T}^{*}$ then:

$$
\operatorname{Cov}_{A}\left(T^{*}, \mathrm{OR}\right)=0
$$

and so:

$$
b_{p}(\mathrm{~T}, \mathrm{~W} 10)=\frac{\operatorname{Cov}_{A}(\mathrm{~T}, \mathrm{OR})}{\operatorname{Cov}_{A}(\mathrm{~W} 10, \mathrm{OR})}
$$

therefore:

$$
r_{p}(\mathrm{~T}, \mathrm{~W} 10)=\frac{r_{A}(\mathrm{~T}, \mathrm{OR}) \sqrt{h^{2}(\mathrm{~T})}}{r_{A}(\mathrm{~W} \text { 10,OR }) \sqrt{h^{2}(\mathrm{~W} 10)}},
$$


where $r_{p}(\mathrm{~T}, \mathrm{~W} 10)$ is the phenotypic correlation between testicular diameter and weight at 10 weeks, $r_{A}(\mathrm{~T}, \mathrm{OR})$ and $r_{A}(\mathrm{~W} 10, \mathrm{OR})$ are the genetic correlations of ovulation rate with testicular diameter and weight at 10 weeks respectively and $h^{2}(\mathrm{~T})$ and $h^{2}(\mathrm{~W} 10)$ are the heritabilities of testicular diameter and body weight at 10 weeks respectively.

If it is assumed that selection on $\mathrm{T}^{*}$ would have produced no correlated response in ovulation rate, as did selection on the more complex index actually used in this study, then (1) can be used to draw conclusions about the relative effectiveness of selection for testicular diameter versus selection for body weight at 10 weeks as means of producing correlated responses in ovulation rate. From Hill (1985) the value of selection on testicular diameter relative to selection directly on ovulation rate is proportional to:

$$
\frac{r_{A}(\mathrm{~T}, \mathrm{OR}) \sqrt{h^{2}(\mathrm{~T})}}{\sqrt{h^{2}(\mathrm{OR})}}
$$

An equivalent formula can be derived for the value of selection on body weight at 10 weeks relative to selection directly on ovulation rate:

$$
\frac{r_{A}(\mathrm{~W} 10, \mathrm{OR}) \sqrt{h^{2}(\mathrm{~W} 10)}}{\sqrt{h^{2}(\mathrm{OR})}}
$$

Therefore, the relative effectiveness of selection on testicular diameter versus selection on body weight at 10 weeks as indirect indicators of genetic merit is given by the ratio of (2) to (3), which, in this case, from (1) is equivalent to $r_{p}(\mathrm{~T}, \mathrm{~W} 10)$. In this experiment $r_{p}(\mathrm{~T}, \mathrm{~W} 10)$ was estimated to be 0.72 , and in any event it must be less than unity. The correlated rate of response in ovulation rate selecting on testicular diameter would therefore only be predicted to be $72 \%$ of that obtained from selection on 10-week body weight. It is not possible to predict from these results what the absolute rates of response would be, and whether either trait would provide an efficient indirect indicator of genetic merit for ovulation rate.

\section{References}

Atkins, K.D. (1984) The Estimation of Responses to Selection. Ph.D. thesis, University of Edinburgh.

Baker, R.J. \& Nelder, J.A. (1978) The GLIM System. Numerical Algorithms Group, Oxford.

Bradford, G.E. (1972) Genetic control of litter size in sheep. J. Reprod. Fert., Suppl. 15, 23-41.

Burfening, P.J. \& Tulley, D. (1986) Effect of selection for high and low prolificacy on libido and scrotal circumference. Proc. 2nd Wld Congr. on Genetics Applied to Livestock Production, Madrid, Spain, VII, pp. 536-542. Editorial Garsi, Madrid, Spain.

Haley, C.S., Cameron, N.D., Slee, J. \& Land, R.B. (1987) Indirect selection. In New Techniques in Sheep Production, pp. 113-123. Eds I. F. M. Marai \& J. B. Owen. Butterworth, London.

Hanrahan, J.P. \& Quirke, J.F. (1982) Selection on ovulation rate in sheep aided by the use of superovulation and egg transfer. Proc. Wld Congr. of Sheep and Beef Cattle Breeding, Palmerston North 1, 329-335.

Harvey, W.R. (1977) Users Guide to LSML76. Mixed Model Least Squares and Maximum Likelihood Program. Ohio State University, Ohio, USA.

Hill, W.G. (1985) Detection and genetic assessment of physiological criteria of merit within breeds. In Genetics of Reproduction in Sheep, pp. 319-331. Eds R. B. Land \& D. W. Robinson. Butterworth Scientific, London.
Hill, W.G., Marks, P.J., Jenkins, J.C. \& Land, R.B. (1990) Selection on testis size as an indicator of maturity in growing animals: 2 . Correlated responses in reproductive rate. Genet. Sel. Evol. (In press).

Islam, A.B.M.M., Hill, W.G. \& Land, R.B. (1976) Ovulation rates of lines of mice selected for testis weight. Genet. Res. 27, 23-32.

James, J.W. (1986) Cumulative selection differentials and realized heritabilities with overlapping generations. Anim. Prod. 42, 411-415.

Knight, T.W. (1984) Testicular growth and size in rams from flocks of different reproductive potential. N.Z. Jl agric. Res. 27, 179-187.

Land, R.B. (1973) The expression of female sex-limited characters in the male. Nature, Lond. 241, 208-209.

Land, R.B. \& McClelland, T.H. (1971) The performance of Finn-Dorset sheep allowed to mate four times in two years. Anim. Prod. 13, 647-641.

Land, R.B., Carr, W.R. \& Lee, G.J. (1980) A consideration of physiological criteria of reproductive merit in sheep. In Selection Experiments in Laboratory and Domestic Animals, pp. 147-160. Ed. A. Robertson. Commonwealth Agricultural Bureaux, Slough.

Land, R.B., Gauld, I.K., Lee, G.J. \& Webb, R. (1982) Further possibilities for manipulating the reproductive process. In Future Developments in the Genetic Improvement of Animals, pp. 59-87. Eds J. S. Downloaded from Bioscientifica.com at 04/26/2023 01:10:37PM 
Barker, K. Hammond \& A. E. McClintock. Academic Press, Sydney.

Lee, G.J. \& Land, R.B. (1985) Testis size and LH response to $\mathrm{LH}-\mathrm{RH}$ as male criteria of female reproductive performance. In Genetics of Reproduction in Sheep, pp. 333-342. Eds R. B. Land \& D. W. Robinson. Butterworth, London.

McNeilly, J.R., Fordyce, M., Land, R.B., Lee, G.J. \& Webb, R. (1986) Endocrine differences in rams after genetic selection for testis size. J. Reprod. Fert. 76, 131-140.

Meat and Livestock Commission (1987) Breeding objectives in British flocks. In Sheep Yearbook, pp. 55-58. Meat and Livestock Commission, Bletchley.

Newman, J.A., Rahnfeld, G.W. \& Fredeen, H. (1973) Selection intensity and response to selection for yearling weight in beef cattle. Can. J. Anim. Sci. 53, 1-12.

Nitter, G. (1987) Economic response to increasing genetic potential for reproductive performance. In New Techniques in Sheep Production, pp. 271-280. Eds I. F. M. Marai \& J. B. Owen. Butterworth, London.

Pattie, W.A. (1965) Selection for weaning weight in Merino sheep. 1. Direct response to selection. Aust. J. exp. Agric. Anim. Husb. 5, 353-360.

Purvis, I.W., Piper, L.R., Edey, T.N. \& Kilgour, R.J. (1988) The genetic relationship between ovulation rate and testicular diameter in a random-breeding Merino flock. Livest. Prod. Sci. 18, 35-54.

Quaas, R.L. (1976) Computing the diagonal elements and inverse of a large numerator relationship matrix. Biometrics 32, 949-953.

Ricordeau, G., Blanc, M.R. \& Bodin, L. (1984) Teneurs plasmatiques en FSH et LH des agneaux mâles et femelles issus de béliers Lacaune prolifiques et non prolifiques. Génét. Sél. Evol. 16, 195-210.

Ricordeau, G., Poivey, J.P., Bodin, L., Barillet, M. \& Roussely, M. (1986) Importance of testicular measurements on young males tested on individual performance for improvement of their daughters prolificacy: Application to the selection scheme on Lacaune milking breed. Proc. 3rd Wld Congr. on Genetics Applied to Livestock Production, Lincoln, Nebraska. XI, pp. 72-77.

Ricordeau, G., Pelletier, J., Courot, M. \& Thimonier, J. (1979) Phenotypic and Genetic relationships between endocrine criteria and testicular measurements of young Romanov rams and the ovulation rates at 8 months of their half-sisters. Annls Génét. Sél. Anim. 11, 145-159.

Schinckel, A., Johnson, R.K., Pumphrey, R.A. \& Zimmerman, D.R. (1983) Testicular growth in boars of different genetic lines and its relationship to reproductive performance. J. Anim. Sci. 58, 1065-1076.

Thompson, R. \& Juga, J. (1989) Cumulative selection differentials and realized heritabilities. Anim. Prod. 49, 203-208.

Toelle, V.D. \& Robison, O.W. (1985a) Estimates of genetic correlations between testes measurements and female reproductive traits in cattle. J, Anim. Sci. 60, 89-100.

Toelle, V.D. \& Robison, O.W. (1985b) Estimates of genetic relationship between testes measurements and female reproductive traits in swine. $Z$. Tierzüch. Züchtungsbiol. 102, 125-132.

Walkey, J.R.W. \& Smith, C. (1980) The use of physiological traits in genetic selection for litter size in sheep. J. Reprod. Fert. 59, 83-88.

Received 10 June 1989 